\title{
The Follicle-Stimulating Hormone (FSH) Threshold/Window Concept Examined by Different Interventions with Exogenous FSH during the Follicular Phase of the Normal Menstrual Cycle: Duration, Rather Than Magnitude, of FSH Increase Affects Follicle Development*
}

\author{
IZAÄK SCHIPPER, WIM C. J. HOP, AND BART C. J. M. FAUSER \\ Division of Reproductive Medicine, Department of Obstetrics and Gynecology (I.S., B.C.J.M.F.), and \\ the Department of Epidemiology and Biostatistics (W.C.J.H.), Dijkzigt Academic Hospital and \\ Erasmus University Medical School, Rotterdam, The Netherlands
}

\begin{abstract}
According to the threshold concept, FSH concentrations need to surpass a distinct level to stimulate ovarian follicle growth. The window concept stresses the significance of a limited duration of elevated FSH levels above the threshold for single dominant follicle selection. The aim of this study was to investigate effects on follicle growth of increased FSH levels, differing in duration and magnitude of elevation, during the follicular phase. Twenty-three normo-ovulatory (cycle length, 26-31 days), young (age, 20-31 yr) women volunteered for this study. In all subjects a series of daily transvaginal sonography scans of the ovaries and blood sampling [for FSH and estradiol $\left(\mathrm{E}_{2}\right)$ determinations] were performed during two consecutive cycles. The first study cycle (control cycle) started 10 days after urinary assessment of the LH surge in the preceding cycle $\left(\mathrm{Day}_{\mathrm{LH}}\right)$ and was concluded on the day of ovulation assessed by transvaginal sonography scans. The second series of daily monitoring (intervention cycle) started 10 days after Day $_{\mathrm{LH}}$ in the control cycle. After randomization, subjects received either 375 IU urinary FSH, sc, as a single injection on $\mathrm{Day}_{\mathrm{LH}+14}$ (group $\mathrm{A} ; \mathrm{n}=11$ ) or 75 IU daily from $\mathrm{Day}_{\mathrm{LH}+19}$ until $\operatorname{Day}_{\mathrm{LH}+23}$ (group B; $\mathrm{n}=12$ ).

In group A, FSH levels increased on the day after injection to a median concentration of $10.1 \mathrm{IU} / \mathrm{L}$, which was 1.9 times higher $(P<$ 0.01 ) than levels on matching days during the control cycle. Concentrations returned to basal levels 3 days after injection. In group B, a moderate elevation of FSH concentrations (15\% increase; $P<0.05$ )
\end{abstract}

was observed compared to levels during the control cycle. In group A, $\mathrm{E}_{2}$ concentrations increased $(P=0.03) 1$ day after FSH injection and returned to baseline levels within 2 days. In group $\mathrm{B}, \mathrm{E}_{2}$ levels started to increase after the first injection of FSH and remained significantly higher $(P<0.01)$ during the following 5 days compared to those on matching days in the control cycle. Compared to matching days in the control cycle an increased number of follicles $8-10 \mathrm{~mm}$ in size was found in group A $(P<0.01)$ during the period from Day $_{L+14}$ until Day $_{\mathrm{LH}+19}$, without an increase in follicles $10 \mathrm{~mm}$ or larger thereafter. In contrast, in group B, the numbers of both 8- to $10-\mathrm{mm}$ and $10-\mathrm{mm}$ or larger follicles were higher during the period from $\mathrm{Day}_{\mathrm{LH}+19}$ until Day $_{\mathrm{LH}+24}$ in group B $(P=0.02$ and $P<0.01$, respectively).

Results from the present study suggest that a brief, but distinct, elevation of FSH levels above the threshold in the early follicular phase does not affect dominant follicle development, although the number of small antral follicles did increase. In contrast, a moderate, but continued, elevation of FSH levels during the mid to late follicular phase (effectively preventing decremental FSH concentrations) does interfere with single dominant follicle selection and induces ongoing growth of multiple follicles. These findings substantiate the FSH window concept and support the idea of enhanced sensitivity of more mature follicles for stimulation by FSH. These results may provide the basis for further investigation regarding ovulation induction treatment regimens with reduced complication rates due to overstimulation. (J Clin Endocrinol Metab 83: 1292-1298, 1998)

\begin{abstract}
A SFSH LEVELS increase during the luteo-follicular transition of the menstrual cycle, a cohort of small antral follicles is prevented from undergoing atresia and is stimulated for further development (1-4). The FSH threshold concept has been proposed, emphasizing the need for serum FSH to surpass a distinct concentration to induce ovarian activity (5-7). Based on observations during gonadotropin
\end{abstract}

Received July 29, 1997. Revision received November 14, 1997. Accepted January 5, 1998.

Address all correspondence and requests for reprints to: Prof. B. C. J. M. Fauser, Division of Reproductive Medicine, Department of Obstetrics and Gynecology, Dijkzigt Academic Hospital, Dr. Molewaterplein 40, 3015 GD Rotterdam, The Netherlands.

* This work was supported by the Netherlands Organization for Scientific Research (NWO/GB-MW 903-44-109) and Stichting Voortplantingsgeneeskunde Rotterdam. induction of ovulation, Brown suggested that an elevation of FSH concentrations only $10-30 \%$ above the threshold level is sufficient to stimulate normal follicle development, whereas a further increase causes excessive stimulation (5). Indeed, multiple follicle development and ovulation have been attributed to higher elevations of FSH above the threshold level $(8,9)$.

Circulating FSH levels decrease in the late follicular phase of the normal menstrual cycle, supposedly due to increased secretion of ovarian factors such as estradiol $\left(E_{2}\right)$ and inhibin $\mathrm{B}$, which exert negative feedback at the hypothalamic-pituitary level $(10,11)$. The strict relationship between decreasing FSH concentrations and dominant follicle development in the normal menstrual cycle has been established recently by our group (12), emphasizing the importance of decreasing $\mathrm{FSH}$ levels in securing single dominant follicle selection. 
Apparently, the maturing dominant follicle requires less FSH to continue its growth $(13,14)$. This may be due to intraovarian changes in growth factors, which up-regulate the FSH sensitivity of follicles in more advanced developmental stages (15). As a consequence, other recruited follicles lack sufficient stimulation by FSH and enter atresia. In this regard, the "FSH-gate" (2) or "FSH-window" (16) concept has been proposed, which adds the element of time to the FSH threshold theory and emphasizes the significance of a transient increase in FSH above the threshold level for single dominant follicle development. Indeed, as has been demonstrated in primates, interference with the decrease in $\mathrm{FSH}$ levels in the midfollicular phase overrides selection of a single dominant follicle (17). Moreover, administration of gonadotropins for induction of ovulation in the human, applying a decremental dose regimen, has proven successful in reducing the incidence of multiple follicle development (18, 19).

Further insight into the significance of the pattern of FSH stimulation for recruitment and dominant follicle selection may provide a basis for understanding mechanisms underlying follicle maturation arrest in polycystic ovary syndrome patients, for improved treatment regimens for gonadotropin induction of ovulation, and for effective suppression of residual ovarian activity during the pill-free interval of steroid contraception (4). The principal aim of the present study was to examine to what extent elevation of FSH levels, differing in duration and magnitude, would affect follicle development. For this purpose, FSH was administered at different times and dosages to women exhibiting normal ovarian function to elicit either an increase in FSH concentrations far above the threshold level in the early follicular phase or a moderate, but prolonged, FSH increase in the mid to late follicular phase.

\section{Subjects and Methods}

\section{Subjects and study design}

This study was approved by the ethics review committee of the Academic Hospital and Erasmus University Medical School (Rotterdam, The Netherlands). A total of 26 study subjects was selected from respondents to an advertisement in a local newspaper. Inclusion criteria were age between 20-33 yr, regular menstrual cycles for at least 3 months before the study (cycle lengths between 26-31 days), and no oral contraceptive use or other medical or hormonal treatment for at least 3 months before study initiation. In addition, subjects were required to be of normal weight (body mass index, $19-25 \mathrm{~kg} / \mathrm{m}^{2}$ ) and to have never received treatment for infertility. During the study, subjects were required to use sufficient contraceptive measures, such as intrauterine devices, tubal ligation, or condoms. Informed written consent was obtained from each participant, and all 26 subjects were paid for their participation. Fourteen subjects had been pregnant previously.

Subjects were studied during three subsequent cycles. From 10 days after the onset of menses, subjects assessed the LH surge using a urinary LH test (Clear-Plan One Step, Unipath, Bedford, UK) according to the manufacturer's instructions. Six or 7 days after a positive urinary $\mathrm{LH}$ test, a blood sample was taken for assessment of midluteal progesterone (P). From 12 days after the LH surge, a series of daily transvaginal ultrasound scans (TVS) and blood sampling was performed (control cycle). Daily investigations for each subject took place between $1200-$ $1700 \mathrm{~h}$ and were concluded on the day of sonographically assessed ovulation [decrease in size of $>50 \%$ of the largest $(\geq 18 \mathrm{~mm}$ ) follicle]. Normal ovulation was confirmed by assessment of elevated P levels $(>18 \mathrm{nmol} / \mathrm{L}) 6$ or 7 days later (12)

A second series of daily TVS and blood sampling started 10 days after the onset of the LH surge (intervention cycle). The day of the LH surge $\left(\right.$ Day $\left._{\mathrm{LH}}\right)$ was assessed by measurement of serum LH in the control cycle and was defined as the day on which the LH level was highest or as the first LH level that was at least 3 times higher than the level on the previous day. On the 12th day after the LH surge, subjects were randomly assigned to one of two intervention schedules (designated group $A$ and group B, respectively). Randomization was performed by number in blocks of three pairs by drawing of a sealed envelope indicating the assigned group. The administration of urinary FSH (Metrodin HP of the same batch, provided by Serono Benelux, BV, The Hague, The Netherlands) was performed by a third party, with the assigned protocol unknown to the observer (I.S.). Group A received 375 IU (five ampules) FSH as a single sc injection on the 14th day after the LH surge, effectively increasing FSH concentrations far above the presumed threshold level for a brief period of time in the early follicular phase. Group B received $75 \mathrm{IU}$ (one ampule) of FSH sc daily during 5 consecutive days from 19-23 days after the LH surge, thereby preventing decremental serum FSH concentrations in the mid to late follicular phase, thus widening the FSH window. FSH was administered by qualified nurses shortly after the daily blood withdrawal, with the next blood withdrawal $24 \mathrm{~h}$ later. Daily TVS and blood sampling continued until the day of ovulation in the intervention cycle. Again, normal ovulation was confirmed by assessment of elevated P levels 7 days later.

Sonographic examinations were performed by the same observer (I.S.) using a 6.5-megahertz transvaginal transducer (EUB-415, Hitachi Medical Corp., Tokyo, Japan) as described previously $(12,20)$. In brief, follicle diameter was calculated as the mean diameter measured in two dimensions if both diameters were $9.0 \mathrm{~mm}$ and in three dimensions if at least one diameter was more than $9.0 \mathrm{~mm}$.

\section{Hormone estimations}

Blood samples were centrifuged within $2 \mathrm{~h}$ after withdrawal and stored at $-20 \mathrm{C}$ until assayed. FSH and LH levels were measured by immunoradiometric assay (Medgenix, Fleurus, Belgium) as described previously (21). P levels were assessed by RIA as described previously (22), and $\mathrm{E}_{2}$ levels were estimated using RIA kits provided by Diagnostic Products Corp. (Los Angeles, CA). Intra- and interassay coefficients of variation were less than $3 \%$ and less than $8 \%$ for $\mathrm{FSH}$, less than $5 \%$ and less than $15 \%$ for $\mathrm{LH}$, less than $16 \%$ and less than $17 \%$ for $\mathrm{P}$, and less than $15 \%$ and less than $18 \%$ for $\mathrm{E}_{2}$, respectively. All samples from one subject were run in the same assay.

\section{Data analysis}

Data are presented as the mean \pm SD if distributed normally or as the median and range if distributed otherwise. The time scale used is based on the day of the preceding $\mathrm{LH}$ surge $\left(\mathrm{Day}_{\mathrm{LH}}\right)$. The day of selection of the dominant follicle is defined as the day on which a given follicle was $10 \mathrm{~mm}$ or larger together with an enlargement of this follicle during subsequent days until ovulation, as described previously $(12,20)$. The day of the $\mathrm{E}_{2}$ rise is defined as the day during the follicular phase on which $E_{2}$ concentrations were significantly higher compared to those on the preceding days and continued to increase thereafter until ovulation. This was estimated using piecewise linear regression relating $\log \left(\mathrm{E}_{2}\right)$ to cycle day, as described previously (12).

The effects of both interventions was estimated by comparison of the area under the curve (AUC) of FSH and $\mathrm{E}_{2}$ for a given number of days. AUCs were calculated for each subject individually during two periods of the follicular phase of the menstrual cycle using the trapezoidal rule method. Period 1 was arbitrarily defined to comprise $\mathrm{Day}_{\mathrm{LH}+14}$ until Day $_{\mathrm{LH}+19}$, and period 2 comprised $\mathrm{Day}_{\mathrm{LH}+19}$ until Day $\mathrm{LH}_{\mathrm{LH}+24}$ based on FSH administration regimens. As a reflection of follicle growth, the total number of follicles observed (divided into size classes of 8-10 $\mathrm{mm}$ and $\geq 10 \mathrm{~mm}$ ) was calculated for the same periods.

Statistical analysis was performed using Wilcoxon's test for matched pairs for comparison between the control cycle and the intervention cycle for each group. Comparisons of outcome measures between both randomized groups were performed using the Mann-Whitney U test. Power analysis $(=0.20)$ showed that the sizes of both intervention groups allowed for detection $(=0.05)$ of differences in outcome parameters of 1.1 SD. Spearman's correlation coefficients are indicated. $P$ values are twosided, with 0.05 taken as the limit for statistical significance. 


\section{Results}

FSH and $E_{2}$ levels during control and intervention cycles

Two of the 26 subjects were excluded from further analysis due to an irregular control cycle and/or anovulation during the control cycle. A third subject was excluded due to multiple persisting cysts at the onset of the intervention cycle in combination with an insufficient luteal phase in the preceding control cycle. All remaining 23 subjects were ovulatory in both the control and the intervention cycle, as assessed by TVS and elevated serum P levels $(38 \pm 10 \mathrm{nmol} / \mathrm{L}) 7$ days after sonographically assessed ovulation. After the control cycle, 11 subjects were randomized for the intervention cycle into group A, and 12 were randomized into group B. With regard to the distribution of age and body mass index, no significant differences were found between the two groups (data not shown).

Due to the design of the study, serum FSH levels are presented with the LH surge from the preceding cycle as the point of reference. This is for reasons of comparison between the control and intervention cycles and does not represent accurately individual patterns of serum FSH concentrations. In the intervention cycle in group A (Fig. 1a, top right panel), in all subjects FSH levels reached a maximum level 1 day after sc administration of 375 IU FSH on Day $\mathrm{LH}_{\mathrm{LH}+14}$, with a median concentration of $10.1 \mathrm{IU} / \mathrm{L}$ (range, 7.9-13.9). FSH levels remained significantly elevated $(P<0.01)$ for 2 days and returned to levels similar to those in the control cycle on Day $_{\mathrm{LH}+17}$ [median levels, 5.0 (range, 2.4-7.3) and 5.5 (range, 4.1-9.6) IU/L in control and intervention cycles, respectively]. In all subjects a second, endogenous increase in FSH reached its maximum level on $\mathrm{Day}_{\mathrm{LH}+21}$ (range, $\mathrm{Day}_{\mathrm{LH}+18}$ to $\left.\mathrm{Day}_{\mathrm{LH}+30}\right)$. The median concentration of these maximum FSH levels in the intervention cycle was not different from the corresponding levels in the control cycle [5.7 (range, 3.7-7.4) and 5.7 IU/L (range, 4.2-6.6), respectively]. In group $\mathrm{B}$, daily sc administration of 75 IU FSH on Day $\mathrm{LH}_{\mathrm{LH}}$ until $\mathrm{Day}_{\mathrm{LH}+23}$ resulted in FSH levels 15\% (range, 6-37\%) higher compared than those on matching days during the control cycle $(P<0.05$; Fig. 1a, bottom right panel).

In response to administration of 375 IU FSH on Day $\mathrm{DHH}_{\mathrm{L}+14}$ in group $\mathrm{A}, \mathrm{E}_{2}$ levels were significantly elevated on $\mathrm{Day}_{\mathrm{LH}+15}$ and Day ${ }_{\mathrm{LH}+16}$ compared to levels before injection $(P<0.01)$ and to levels on matching days in group $\mathrm{B}(P<0.01)$. After this increase, $E_{2}$ levels returned to basal levels on Day ${ }_{L H+17}$ (Fig. 1b, top right panel). One day after administration of the first injection of 75 IU FSH in group $B, E_{2}$ levels increased significantly compared to those during both the control cycle and the intervention cycle of group A on matching days $(P<$ $0.01)$. Although the day of the $E_{2}$ rise occurred earlier in the intervention cycle of group $\mathrm{B}$ than in the control cycle $(P=$ $0.03)$, the median preovulatory $E_{2}$ levels were not statistically different [1040 (range, 380-1800) and 900 (390-1300) pmol/L, respectively]. Furthermore, the median preovulatory $\mathrm{E}_{2}$ levels in group B were not statistically different from those in group A (810 pmol/L; range, 550-1100).

\section{Follicle development during control and intervention cycles}

Figure 2 shows the mean number of 8-mm follicles in both ovaries during the follicular phases of the control cycle and the intervention cycle of groups A and B. Follicles less than $8 \mathrm{~mm}$ have been omitted from the graphs because analysis of follicle numbers in smaller size classes did not display significant differences (data not shown).

After administration of 375 IU FSH on $\mathrm{Day}_{\mathrm{LH}+14}$ in group $\mathrm{A}$, an increase in the number of 8 - to $10-\mathrm{mm}$ follicles was observed $(P<0.05)$, however without ongoing growth to sizes beyond $10 \mathrm{~mm}$ on subsequent days. In group $\mathrm{B}$, daily administration of 75 IU FSH from Day $_{\mathrm{LH}+19}$ until Day $_{\mathrm{LH}+23}$ did not result in a statistically significant increase $(P=0.8)$ in the mean number of 8- to 10-mm follicles compared to that in the control cycle. However, during the following days an increasing number of follicles $10 \mathrm{~mm}$ or larger was observed $(P<0.05)$, suggesting ongoing growth of these follicles.

\section{AUC for FSH and $E_{2}$ and the total number of follicles during control and intervention cycles}

The median AUC for FSH of period 1 (from Day ${ }_{\mathrm{LH}+14}$ until Day $\left._{\mathrm{LH}+19}\right)$ in the intervention cycle in group A was significantly higher compared to that during the same period in the control cycle [median AUC period 1, 37 (range, 32-49) vs. 27 (range, 17-34) IU day / L; $P=0.004]$. The AUC for FSH during period 2 in the intervention cycle in group B (Day ${ }_{\mathrm{LH}+19}$ until $\left.\mathrm{Day}_{\mathrm{LH}+24}\right)$ was significantly higher than that in the control cycle [34 (range, 23-46) and 28 (range, 21-39) IU/day/L, respectively; $P=0.002$; Fig. 3 , top panel]. During the intervention cycle, the median AUCs of period 1 in group A and period 2 in group $B$ were not significantly different $(P=0.15)$ from each other.

Despite the short, but significant, increase in $\mathrm{E}_{2}$ levels on $\mathrm{Day}_{\mathrm{LH}+15}$ and $\mathrm{Day}_{\mathrm{LH}+16}$ in response to administration of FSH in group $A$, the AUC for $E_{2}$ of period 1 was not significantly different from that of the control cycle [1440 (range, 940-1853) vs. 1162 (range, 678-3604) pmol/day / L; $P=0.33]$. In contrast, in group $B$, a significantly higher AUC for $E_{2}$ was observed during period 2 of the intervention cycle compared to that during the control cycle [2144 (range, 1799-2799) and 1361 (range, 992-2463) pmol/day /L, respectively; $P<0.01]$. Comparing both groups during period 2 in the intervention cycle, the AUC for $E_{2}$ in group B was greater than that in group $A$ [median AUC, 2144 (range, 1799-2799) vs. 1223 (range, 8182423) $\mathrm{pmol} /$ day/L, respectively; $P<0.01$ ].

After administration of 375 IU FSH on $\mathrm{Day}_{\mathrm{LH}+14}$ in group A, a significant increase in small $(8-10 \mathrm{~mm})$ follicles was observed during period 1 compared to that during a similar period in the control cycle [6 (range, 1-22) vs. 1 (range, $0-8$ ) follicles; $P<0.01$; Fig. 3, bottom panel]. After daily administration of 75 IU FSH in group B, a statistically significant increased number of small $(8-10 \mathrm{~mm})$ follicles as well as an increased number of follicles $10 \mathrm{~mm}$ or larger was observed compared to those during the control cycle during period 2 (Fig. 3, bottom panel, right graph; $P=0.02$ and $P<0.01$, respectively). The latter was reflected by an increase in the number of follicles sized 12-15 mm [mean, 0.9 (range, 0-3) and 2.9 (range, 0-9) in control and intervention cycle, respectively; $P=0.02$ ] and follicles larger than $15 \mathrm{~mm}$ [mean, 0.7 (range, $0-3$ ) and 1.4 (range, $0-4$ ), respectively; $P<0.02$ ]. Furthermore, during period 2, a higher number of follicles 10 
A

Control cycle $(\mathrm{n}=23)$

FIG. 1. Daily follicular phase FSH (A) and $\mathrm{E}_{2}(\mathrm{~B})$ serum concentrations during control (left panel) and intervention cycles in 23 regularly cycling women. Data are shown as the median and range, and the time scale is expressed as days from the preceding LH surge $\left(\operatorname{Day}_{\mathrm{LH}}\right)$. Intervention cycle group A (upper right panel) represents administration of a single sc injection of 375 IU FSH on $\mathrm{Day}_{\mathrm{LH}+14}$, whereas group B (lower right panel) represents five sc injections of 75 IU FSH daily from $\mathrm{Day}_{\mathrm{LH}+19}$ until $\mathrm{Day}_{\mathrm{LH}+23}$. The intervention cycle has been divided arbitrarily into two periods: period 1 $\left(\right.$ Day $_{\mathrm{LH}+14}$ until Day $\left._{\mathrm{LH}+19}\right)$ and period 2 $\left(\right.$ Day $_{\mathrm{LH}+19}$ until Day $\left.\mathrm{DaH}_{\mathrm{LH}+24}\right)$. Asterisks indicate statistically significant higher levels compared to matching days in the control cycle $(P<0.05)$.

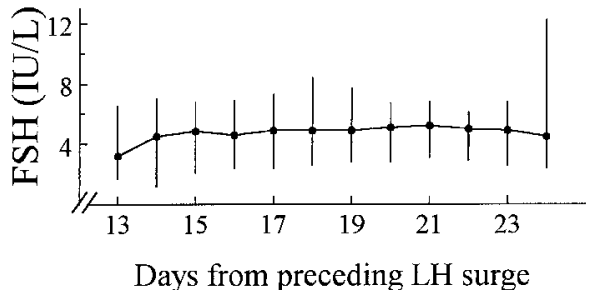

B

Control cycle $(n=23)$

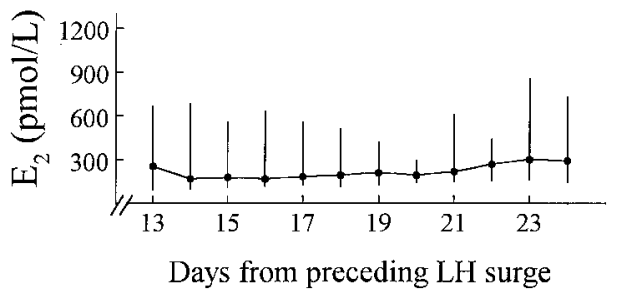

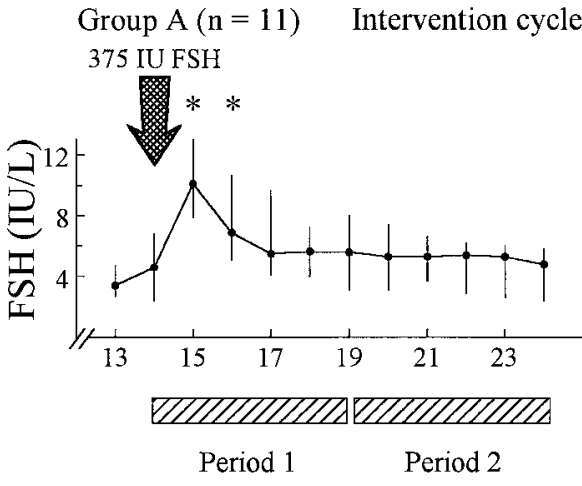

Group B $(n=12)$
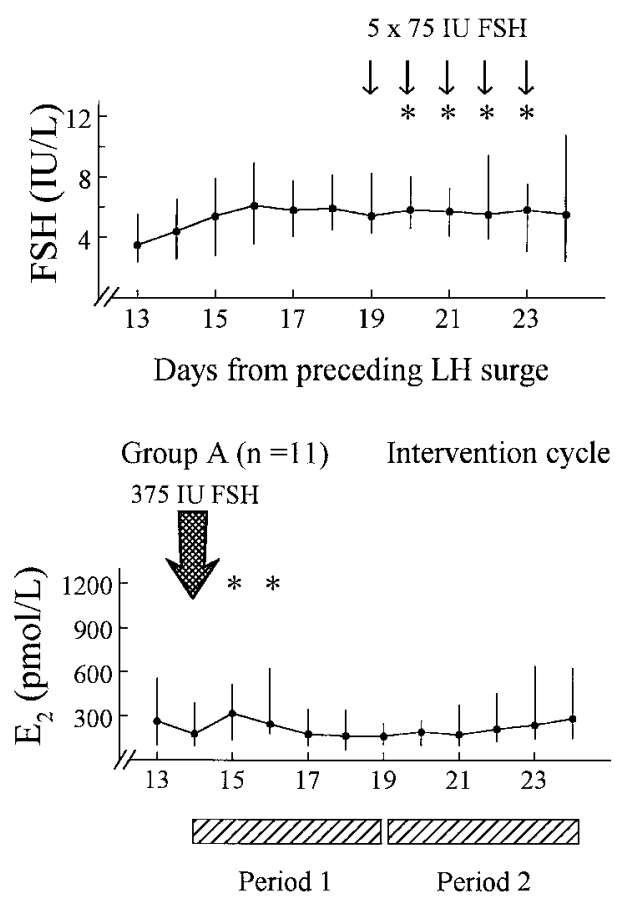

Group B ( $\mathrm{n}=12)$

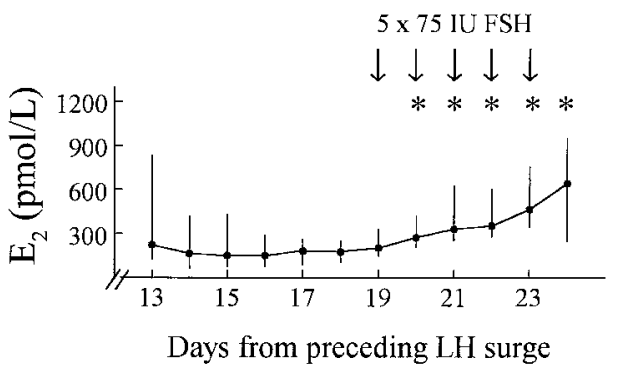

mm or larger was observed in group B compared to group A (mean, 7.4 and 4.3 , respectively; $P=0.05$ ).

\section{Discussion}

At the onset of the menstrual cycle, a cohort of small (2-5 $\mathrm{mm}$ ) antral follicles is present in the ovaries (3). This cohort will continue to grow in response to stimulation by FSH (23), a process referred to as follicle recruitment (1). The FSH threshold concept has been proposed in the late 1970s by
Brown (5) on the basis of serum estrogen levels secreted by developing follicles and more recently has been substantiated by others by sonographical assessment of follicle growth $(9,24)$. According to the FSH threshold concept, increasing FSH concentrations should surpass a distinct level to initiate the final gonadotropin-dependent phase of follicle growth. Some researchers suggest selection of a follicle destined to gain dominance to occur during this period $(23,25,26)$, although direct evidence to support this idea is lacking. 
Follicle size:

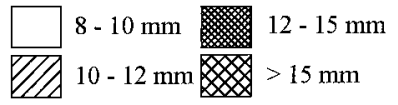

Fig. 2. Number of follicles $(8 \mathrm{~mm})$ during the follicular phase of control (left panel) and intervention cycles in 23 regularly cycling women. Areas represent the mean number of follicles in both ovaries on a given day in all subjects, with shaded areas representing different size classes (see legend). The time scale is expressed as days from the preceding $\mathrm{LH}$ surge $\left(\right.$ Day $\left._{\mathrm{LH}}\right)$. Intervention cycle group A (upper right panel) represents administration of a single sc injection of $375 \mathrm{IU}$ FSH on $\mathrm{Day}_{\mathrm{LH}+14}$, whereas group B (lower right panel) represents five sc injections of 75 IU FSH daily from $\mathrm{Day}_{\mathrm{LH}+19}$ until Day $\mathrm{LH}_{\mathrm{LH}+23}$. The intervention cycle has been divided arbitrarily into two periods: period $1\left(\right.$ Day $_{\mathrm{LH}+14}$ until $\left.\mathrm{Day}_{\mathrm{LH}+19}\right)$ and period $2\left(\right.$ Day $_{\mathrm{LH}+19}$ until $\left.^{\mathrm{Day}} \mathrm{LH}_{\mathrm{LH}+24}\right)$.

$$
\text { Control cycle }(n=23)
$$

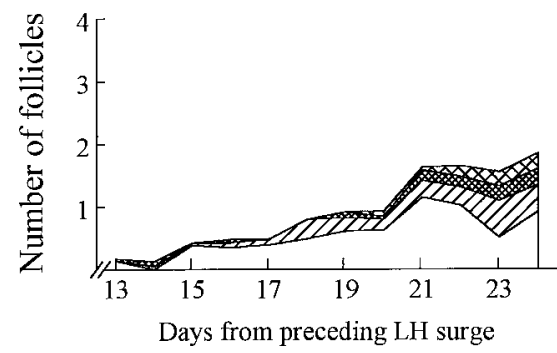

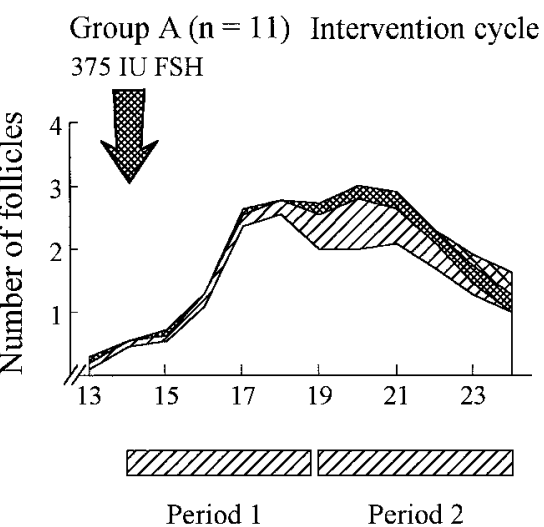

Group B $(\mathrm{n}=12)$

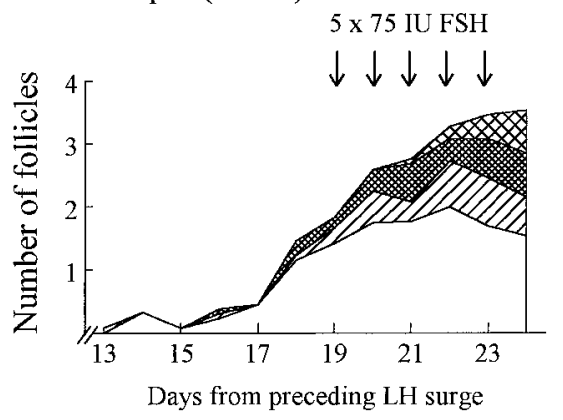

Moreover, it has been hypothesized that follicles exhibit different degrees of FSH sensitivity at the time of recruitment. The follicle with the highest sensitivity will benefit most from increasing FSH levels and will subsequently gain dominance (27).

As opposed to ovarian hyperstimulation for in vitro fertilization, the aim of induction of ovulation is to stimulate single dominant follicle development and ovulation. FSH levels are elevated above the threshold by daily administration of gonadotropins. Conventional treatment protocols are often complicated by the occurrence of multiple follicle development, which may result in ovarian hyperstimulation syndrome or multiple pregnancies. It has been proposed that multiple follicle development is induced by elevating FSH concentrations far above the threshold (6). By starting with a lower dose of gonadotropins and stepwise small increments, chances of inducing monofollicular growth should increase with a concomitant reduction of complications. This regimen is referred to as the low dose, step-up protocol (28, 29). However, these stimulation protocols are characterized by FSH concentrations remaining above the threshold throughout the follicular phase, which may interfere with single dominant follicle selection. Indeed, it has been demonstrated that the extent of accumulation of FSH in the late follicular phase determines the magnitude of the ovarian response (30).

FSH concentrations reach a maximum in the early follicular phase of the normal menstrual cycle and decrease thereafter. The significance of this timely decrease in FSH to ensure monofollicular development has been demonstrated previously in primates $(13,31)$ as well as in the human (12). These findings indicate that the dominant follicle requires less FSH to continue its development, probably due to induction of locally acting factors, such as various growth factors or the induction of $\mathrm{LH}$ receptors that enhance FSH sensitivity (15). It is less likely that factors interfering with $\mathrm{FSH}$ receptor binding and activation are involved in this regulation (32). Although the dominant follicle continues its maturation, decreasing FSH concentrations fall below the threshold level of less mature follicles of the recruited cohort. Consequently, these follicles cannot sustain their growth and become atretic. On the basis of these findings, the FSH window concept has been proposed, stressing the significance of the (limited) duration of FSH elevation above the threshold level rather than the height of the elevation of FSH for single dominant follicle selection $(4,16)$. In line with the FSH window concept, application of a decremental dose regimen for safe and effective gonadotropin induction of ovulation, mimicking the dynamics of normal follicular phase FSH levels, has proven successful $(18,19)$.

The present study, administering exogenous FSH to regularly cycling women, demonstrates that a distinct, but short, increase in FSH levels in the early follicular phase around the onset of menses induces an increased growth of small follicles during subsequent days. However, dominant follicle growth (beyond a size of $10 \mathrm{~mm}$ ) is not affected. In contrast, a slight, but extended, elevation of FSH levels during the mid to late follicular phase, effectively preventing the physiological decrease in FSH concentrations, did result in the development of multiple dominant follicles. The present results correspond partly with conclusions drawn from a recent study (33). A single injection of 450 IU FSH to ovulatory women (suffering from unexplained infertility) on cycle day 2 and additional FSH administration (one to three ampules 
Control cycle

$$
(\mathrm{n}=23)
$$

Fig. 3. AUC of FSH (top panel), $\mathrm{E}_{2}$ (middle panel), and total follicle number (bottom panel) during two periods in the control cycle and intervention cycle in 23 regularly cycling women. Period 1 is defined as $\mathrm{Day}_{\mathrm{LH}+14}$ until Day $_{\mathrm{LH}+19}$, and period 2 from $\mathrm{Day}_{\mathrm{LH}+19}$ until Day $_{\mathrm{LH}+24}$. Boxes indicate 25th and 75th percentiles, with the horizontal line representing the median value. Whiskers span the range between the 5th and 95th percentiles of the data. a, Significantly different $(P<0.05)$ comparing a similar period from the intervention cycle vs. the control cycle. b, Significantly different $(P<0.05)$ comparing a similar period from group $\mathrm{B} v$ s. group A. $c, P=0.07$, comparing a similar period in group B vs. group A.

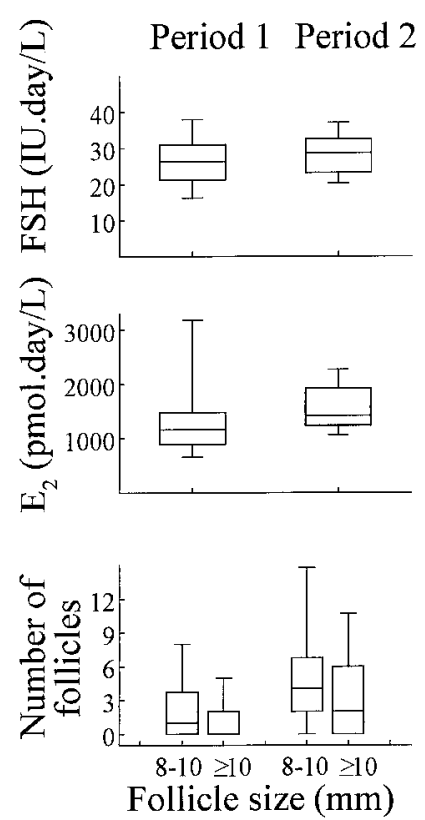

Intervention cycle

Group A $(\mathbf{n}=11)$

Period 1 Period 2
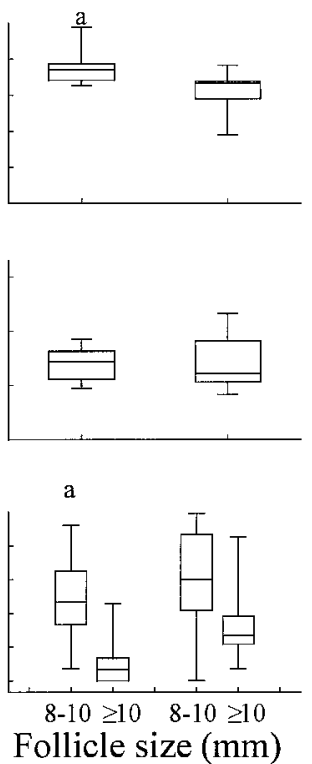

Intervention cycle

Group B ( $\mathrm{n}=12)$

Period 1 Period 2
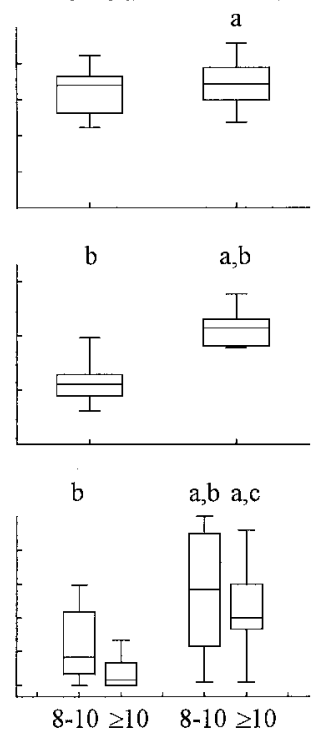

Follicle size (mm) daily) during subsequent days resulted in an increased number of preovulatory follicles dependent on the dose of FSH administered. The researchers concluded that supraphysiological FSH levels in the early follicular phase are a prerequisite for the induction of multiple follicle development, although the number of preovulatory follicles was determined by the height of FSH levels during later stages of the follicular phase. Observations from the present study show that multiple dominant follicle development can be induced by a minor interference with late follicular phase FSH levels only. This is further supported by previous observations from our group suggesting that the magnitude of the late follicular phase decrease in endogenous serum FSH levels determines dominant follicle development and related $\mathrm{E}_{2}$ production (12). In the present study, analysis of the number and size of follicles just before ovulation is of limited significance because exogenous FSH was administered for a fixed number of days relative to the preceding LH surge, resulting in a variable number of days without exogenous FSH before ovulation.

The more than 2-fold increase in FSH concentrations (after administration of 375 IU FSH) in the early follicular phase can be regarded as well above the threshold level. Moreover, observed maximum levels may even be an underestimation of actual maximum concentrations because serum FSH was assessed $24 \mathrm{~h}$ after injection. It has been reported previously that a single injection of FSH in normal men resulted in maximum FSH levels $6-8 \mathrm{~h}$ thereafter, with a $30-50 \%$ decrease after $24 \mathrm{~h}$ (34). Although the same applies for FSH administered to group $\mathrm{B}, \mathrm{FSH}$ concentrations in this group should be considered less above the threshold level than those in group A. Distinct differences in dominant follicle growth comparing both groups stress the significance of timing and duration of the FSH elevation as opposed to the
FSH concentration per se. It may be proposed that recruited follicles increase their sensitivity to FSH during the course of their development $(13,14)$, supposedly due to the induction of a variety of autocrine factors $(15,35-37)$.

Induction of the aromatase enzyme during follicle recruitment has been proposed to determine selection of the dominant follicle $(2,25,38)$. Indeed, $E_{2}$ concentrations in serum increase abruptly from the day a dominant follicle can be visualized by TVS $(12,20)$. Moreover, high $\mathrm{E}_{2}$ concentrations in the antral fluid of follicles beyond $10 \mathrm{~mm}$ in size indicate that aromatase activity is particularly expressed in dominant follicles (39). The present study shows that a short surge of supraphysiological concentrations of FSH is capable of stimulating aromatase activity in small antral follicles. However, $\mathrm{E}_{2}$ production is not sustained even though FSH levels after the surge are similar compared to normal follicular phase concentrations. It may, therefore, be disputed whether induction of aromatase activity in small antral follicles is a determining factor for dominant follicle selection rather than a feature of the dominant follicle after selection.

Results from the present study are supportive of the FSH window concept, which stresses the importance of a limited duration of elevated FSH levels above the threshold, as opposed to the magnitude of FSH increase for follicle selection and dominance. The significance of a timely decrease in FSH levels to ensure single dominant follicle development may be relevant for gonadotropin induction of ovulation protocols (4). As shown recently, ovulation induction applying a decremental dose regimen (step down protocol) may result more frequently in monoovulatory cycles and reduced chances for complications (19). Findings from the present study may also provide a basis for further investigation regarding follicle maturation arrest in polycystic ovary syndrome patients. Furthermore, these results support observations on follicle 
development during and after the pill-free interval in oral contraceptive pill users. During this period, FSH levels may reach normal follicular phase concentrations, sufficient to initiate follicle recruitment (4). Extension of the pill-free interval may thus result in dominant follicle development despite decreasing FSH concentrations due to reinitiation of pill intake (40). In conclusion, elevation of FSH levels high above the threshold level for a short period of time in the early follicular phase does not increase the number of dominant follicles. When a decrease in FSH is prevented in the late follicular phase augmented sensitivity for FSH allows several follicles to gain dominance. Follicle dominance may not be dependent on FSH levels as rigidly as previously assumed. These observations support the FSH window concept and may exhibit clinical implications for ovulation induction treatment and oral contraceptive use.

\section{Acknowledgments}

Metrodin HP was supplied by Mr. H. L. C. Brouwer (Serono Benelux, BV, The Hague, The Netherlands). The authors acknowledge Helene Marijnes, Bert Biering, and Prof. F. H. de Jong for their assistance with hormone assays. The nurses of the Out-Patient Clinic of the Department of Obstetrics and Gynecology, Dijkzigt Hospital, are acknowledged for their assistance with serum collection.

\section{References}

1. Hodgen GD. 1982 The dominant ovarian follicle. Fertil Steril. 38:281-300

2. Baird DT. 1987 A model for follicular selection and ovulation: lessons from superovulation. J Steroid Biochem. 27:15-23.

3. Gougeon A. 1996 Regulation of ovarian follicular development in primates: facts and hypotheses. Endocr Rev. 17:121-155.

4. Fauser BCJM, van Heusden AM. 1997 Manipulation of human ovarian function: physiological concepts and clinical consequences. Endocr Rev. 18:71-106.

5. Brown JB. 1978 Pituitary control of ovarian function: concepts derived from gonadotropin therapy. Aust NZ J Obstet Gynaecol. 18:47-54.

6. Schoemaker J, van Weissenbruch MM, Scheele F, van der Meer M. 1993 The FSH threshold concept in clinical ovulation induction. Balliere Clin Obstet Gynecol. 7:297-308.

7. Ben-Rafael Z, Levy T, Schoemaker J. 1995 Pharmacokinetics of follicle-stimulating hormone: clinical significance. Fertil Steril. 63:689-700.

8. Messinis IE, Templeton AA. 1990 The importance of follicle-stimulating hormone increase for folliculogenesis. Hum Reprod. 5:153-156.

9. van der Meer M, Hompes PGA, Scheele F, Schoute E, Veersema S, Schoemaker J. 1994 Follicle stimulating hormone (FSH) dynamics of low dose step-up ovulation induction with FSH in patients with polycystic ovary syndrome. Hum Reprod. 9:1612-1617.

10. Hotchkiss J, Knobil E. 1994 The menstrual cycle and its neuroendocrine control. In: Knobil E, Neill JD, eds. The physiology of reproduction. New York: Raven Press; 711-750.

11. Groome NP, Illingworth PJ, O'Brien M, et al. 1996 Measurement of dimeric inhibin B throughout the human menstrual cycle. J Clin Endocrinol Metab. 81:1401-1405.

12. van Santbrink EJP, Hop WC, van Dessel HJHM, de Jong FH, Fauser BCJM. 1995 Decremental follicle-stimulating hormone and dominant follicle development during the normal menstrual cycle. Fertil Steril. 64:37-43.

13. Zeleznik AJ, Kubik CJ. 1986 Ovarian responses in macaques to pulsatile infusion of follicle-stimulating hormone (FSH) and luteinizing hormone: increased sensitivity of the maturing folllicle. J Clin Endocrinol Metab. 119:2025-2032.

14. Hall JE, Bhatta N, Adams JM, Rivier JE, Vale WW, Crowley Jr WF. 1991 Variable tolerance of the developing follicle and corpus luteum to gonadotropin-releasing hormone antagonist-induced gonadotropin withdrawal in the human. J Clin Endocrinol Metab. 72:993-1000.

15. Erickson GF. 1996 The ovarian connection. In: Adashi EY, Rock JA, Rosenwaks $\mathrm{Z}$, eds. Reproductive endocrinology, surgery, and technology. Philadephia: Lippincott-Raven; 1141-1160.

16. Fauser BCJM. 1994 Step-down follicle-stimulating hormone regimens in polcystic ovary syndrome. In: Filicori M, Flamigni C, eds. Ovulation induction: basic science and clinical advances. Amsterdam: Elsevier; 153-162.
17. Zeleznik AJ, Hutchison JS, Schuler HM. 1985 Interference with the gonadotropin-suppressing actions of estradiol in macaques overrides the selection of a single preovulatory follicle. Endocrinology. 117:991-999.

18. van Santbrink EJP, Donderwinkel PFJ, van Dessel HJHM, Fauser BCJM. 1995 Gonadotrophin induction of ovulation using a step-down dose regimen: single-centre clinical experience in 82 patients. Hum Reprod. 10:1048-1053.

19. van Santbrink EJP, Fauser BCJM. 1997 Urinary follicle-stimulating hormone for normogonadotropic clomiphene-resistant anovulatory infertility: prospective, randomized comparison between low dose step-up and step-down dose regimens. J Clin Endocrinol Metab. 82:3597-3602.

20. Pache TD, Wladimiroff JW, de Jong FH, Hop WCJ, Fauser BCJM. 1990 Growth patterns of nondominant ovarian follicles during the normal menstrual cycle. Fertil Steril. 54:638-642.

21. Fauser BCJM, Pache TD, Lamberts SWJ, Hop WC, de Jong FH, Dahl KD. 1991 Serum bioactive and immunoreactive luteinizing hormone and follicle-stimulating hormone levels in women with cycle abnormalities, with or without polycystic ovarian disease. J Clin Endocrinol Metab. 73:811-817.

22. de Jong FH, Baird DT, van der Molen HJ. 1974 Ovarian secretion rates of oestrogens and progesterone in normal women and in women with persistent ovarian follicles. Acta Endocrinol (Copenh). 77:575-581.

23. Gougeon A, Testart J. 1990 Influence of human menopausal gonadotropin on the recruitment of human ovarian follicles. Fertil Steril. 54:848-852.

24. van Weissenbruch MM, Schoemaker HC, Drexhage HA, Schoemaker J. 1993 Pharmaco-dynamics of human menopausal gonadotrophin (HMG) and follicle-stimulating hromone (FSH). The importance of the FSH concentration in initiating follicular growth in polycystic ovary-like disease. Hum Reprod. 8:803-821.

25. McNatty KP, Hillier SG, van den Boogaard AMJ, Trimbos-Kemper TCM Reichert Jr LE, van Hall EV. 1983 Follicular development during the luteal phase of the human menstrual cycle. J Clin Endocrinol Metab. 56:1022-1031.

26. Chikazawa K, Araki S, Tamada T. 1986 Morphological and endocrinological studies on follicular development during the human menstrual cycle. J Clin Endocrinol Metab. 62:305-313.

27. Scheele F, Schoemaker J. 1996 The role of follicle-stimulating hormone in the selection of follicles in human ovaries: a survey of the literature and a proposed model. Gynecol Endocrinol. 10:55-66.

28. Polson DW, Mason HD, Saldahna MBY, Franks S. 1987 Ovulation of a single dominant follicle during treatment with low-dose pusatile follicle stimulating hormone in women with polcystic ovary syndrome. Clin Endocrinol (Oxf). 26:205-212.

29. White DM, Polson DW, Kiddy D, et al. 1996 Induction of ovulation with low-dose gonadotropins in polycystic ovary syndrome: an analysis of 109 pregnancies in 225 women. J Clin Endocrinol Metab. 81:3821-3824.

30. Ben-Rafael Z, Strauss III JF, Mastroianni Jr L, Flickinger GL. 1986 Differences in ovarian stimulation in human menopausal gonadotropin treated women may be related to follicle-stimulating hormone accumulation. Fertil Steril. 46:586-592.

31. Zeleznik AJ. 1981 Premature elevation of systemic estradiol reduces serum levels of follicle-stimulating hormone and lengthens the follicular phase of the menstrual cycle in rhesus monkeys. Endocrinology. 109:352-355.

32. Schipper I, ten Hacken PM, Rommerts FFG, Fauser BCJM. 1997 Low levels of follicle-stimulating hormone receptor-activation inhibitors in serum and follicular fluid form normal controls and anovulatory patients with or without polycystic ovary syndrome. J Clin Endocrinol Metab. 82:1325-1331.

33. Lolis DE, Tsolas O, Messinis IE. 1995 The follicle-stimulating hormone threshold level for follicle maturation in superovulated cycles. Fertil Steril. 63:1272-1277.

34. Mizunuma H, Takagi T, Honjyo S, Ibuki Y, Igarashi M. 1990 Clinical pharmacodynamics of urinary follicle-stimulating hormone and its application for pharmacokinetic simulation program. Fertil Steril. 53:440-445.

35. Giudice LC. 1992 Insulin-like growth factors and ovarian follicular development. Endocr Rev. 13:641-669.

36. Findlay JK. 1993 An update on the roles of inhibin, activin, and follistatin as local regulators of folliculogenesis. Biol Reprod. 48:15-23.

37. van Dessel HJHM, Chandrasekher Y, Yap OWS, et al. 1996 Serum and follicular fluid levels of insulin-like growth factor I (IGF-I), IGF-II, and IGFbinding protein-1 and -3 during the normal menstrual cycle. J Clin Endocrinol Metab. 81:1224-1231.

38. Hillier SG, Reichert Jr LE, van Hall EV. 1981 Control of preovulatory follicular estrogen biosynthesis in the human ovary. J Clin Endocrinol Metab. 52:847-856.

39. van Dessel HJHM, Schipper I, Pache TD, van Geldorp H, de Jong FH, Fauser BCJM. 1996 Normal human follicle development: an evaluation of correlations with oestradiol, androstenedione and progesterone levels in individual follicles. Clin Endocrinol (Oxf). 44:191-198.

40. Killick SR. 1989 Ovarian follicles during oral contraceptive cycles: their potential for ovulation. Fertil Steril. 52:580-582. 